\title{
ERRATUM
}

\section{Erratum to : Hybrid Scaffolds Composed of Hyaluronic Acid and Collagen for Cartilage}

\author{
Hyun Jung Kim · Kab Keun Kim· Il Kyu Park • \\ Baek Sun Choi $\cdot$ Jae Ho Kim $\cdot$ Moon Suk Kim
}

Published online : 1 April 2012

(C) Springer-Verlag 2012

Erratum to : Tissue Engineering and Eegenerative Medicine, Vol. 9, N0. 2, pp 57-62 (2012)

DOI $10.1007 / \mathrm{s} 13770-012-0007-7$

A Corresponding author of the paper, Dr. Moon Suk Kim would like to require to you about for author of the paper to withdraw participation. The corresponding author wishes to convey sincere regret to the editor and readers of the journal of Tissue Eng. Regen. Medicine

The online version of the original article can be found under DOI $10.1007 / \mathrm{s} 13770-012-0007-7$

Hyun Jung Kim · Kab Keun Kim · Il Kyu Park · Baek Sun Choi Head of R\&D Center, Genewel Co., Ltd. Hwaseong, 445-924

Korea

Hyun Jung Kim $\cdot$ Jae Ho Kim

Department of Molecular Science and Technology, Ajou University, Suwon, 443-749 Korea 